\title{
Aspects regarding the experimental research of the stressors of the human pregnancy in case of road events
}

\author{
Alexandru Thierheimer ${ }^{1, *}$, Cătălin Alexandru', and Walter Thierheimer ${ }^{2}$ \\ ${ }^{1}$ Transilvania University of Brașov, Product Design, Mechatronics and Environment Department, Brașov, Romania \\ ${ }^{2}$ Transilvania University of Brașov, Food and Tourism Management and Engineering Department, Braşov, Romania
}

\begin{abstract}
In the present paper, it is presented a research facility whose purpose is to analyze the stresses that a pregnant woman's abdomen is feeling during the kicking of the baby. It is able to measure, store and simultaneously process 16 parameters of the human body's movement independently, but also in relation to the movement of the vehicle. The partial information that appears after the processing has finished on a numeric computer, a PC, will allow us to assume the way in which these occupants will behave in all the phases of a car accident: before, during, when coming out of it and after the collision, as well as to design new constructive measures to ensure that there is a non-lethal space within the occupant-interior elementsvehicle frame.
\end{abstract}

\section{Introduction}

The information given by the measurement and data purchasing technical systems after the experimental research was performed make the processing of the said data easy and lead to a series of practical considerations such as: choosing the correct measurement method, adapting and connecting the machines that make up the said technical system, ensuring the conditions for normal functioning by isolating them from exterior factors, the presence of a simple user interface.

The safety of the occupant who is driving the car depends on a significant number of geometricconstructive factors and the ones present in the driver's seat and their technical state, respectively. Among these factors, it can be observed the geometry of the char, the spatial configuration of the board, the passive safety systems, the elastic characteristics of the material used on the bottom and upper part of the chair, the pressurizing characteristics of the airbag systems, etc. At the same time, the safety of the occupant is influenced mainly by the type and the manner in which the collision takes place, by the type of safety belt that exists in the car, by the correlation between the position of the driver with the location where the main force of the collision was applied, as well as the rigidity of the vehicle.

One can say that the safety of the vehicles in general and the safety of the occupants to be more exact are very complex issues that determine the position and the state of the vehicle, as well as the movements of its occupants. Because of this, these issues are given special attention. This field does not focus on theoretical and experimental researches, but the purpose is to identify adequate constructive solutions that would lead to an improvement of the safety of the passengers when they come in contact with sharp bodies or interior elements that can cause damage.

\section{Research methodology}

Starting from these considerations, the present work presents a few aspects regarding experimental research focused on the safety of the driver when the driver is a pregnant woman. For this, it was developed a technically complex measuring system that registers and stores the movement parameters of the victim present in a vehicle, as well as those of the vehicle when it collides with another obstacle.

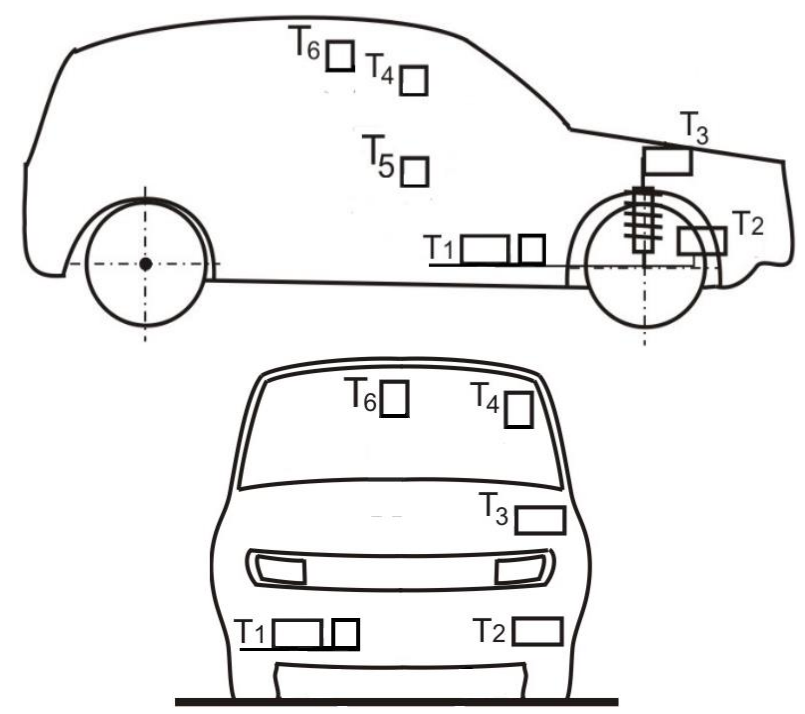

Fig. 1. The sketch to place the sensors

\footnotetext{
* Corresponding author: th.alex@yahoo.com
} 
The main scheme of this technical system is illustrated in Figure 1 and it is made up of the following measurement and registering machines: $T_{l}$ DSD PicDAQ - Dr. Steffan Datentechnik: Data Acquisition System, measurement and storing unit that is specialized in acquiring data in digital form, which contains a triaxial accelerometer [1]. One can notice that the information received using the DSD PicDAQ, Xsens MTi-Inertial Measurement Unit are saved and archived on an Secure Digital SD memory card of $8 \mathrm{~GB}$ in order to process and interpret them later on with the help of a PC computer that contains special Program for the evaluation of vehicle dynamics data PocketDAQ Analyzer, and Next VIEW 2.5 respectively. $T_{2}$ is a potentiometric transducer used to measure the angle the wheel is turning to; $T_{3}$ is a transducer used to measure the internal wing accelerations [2]; $\quad T_{4}$ is a platform Xsens MTi, gyrometer, accelerometer, triaxial magnetometer at the same level with the head; $T_{5}$ platform Xsens MTi, triaxial gyrometer, accelerometer and magnetometer at the same level with the pelvis within the iliac-sacral bone complex; $T_{l}$ is the PocketDAQ triaxial accelerometer mounted in the center of the vehicle.

Considering the components of the data measuring and registering machine, it can be stated that the main measures that were taken into account when researching the stresses that the human body is subjected to, in this case that of a pregnant woman, during a collision focus on the general movement of the driver of the vehicle in relation to the interior elements of the cabin, as well as those of the mechanical stresses of the victim that are created when she comes into contact with these interior elements or with those that end up penetrating her body (her own components or foreign bodies) in the interior of the vehicle and which are strictly related to the bruises of the victim [3]. This can help us follow the kinematic and dynamic behavior of the body during the collision.

In order to perform the experimental research of the passive safety in general and of the degree of protection offered to the occupants of the vehicle, it was obtained a program that focuses on large-scale attempts [4]. This program was meant to store information regarding the mechanism that produces the bruises on the human body, the lower torso area during the events when there is a full frontal collision, a partial centric one or one that took place at a specific angle. All of these tests were performed with different speeds both for the situations when the systems aimed to restrict the movement (airbag, safety belt) worked, as well as for the situations when they were not being used.

The oscilograms that was obtained after processing the information are presented in Figures 2, 3 and 4 respectively, showing the graphic illustration of the variation curves of the measured units that have been measured and filtered with the help of Cebîsev polynomials in the case of NextView, which are fitting for a frontal collision [5]. In Figure 2, it can be seen the monitoring curves of the dynamic behavior of the vehicle such as longitudinal, transversal and vertical acceleration, in this case the rolling, pitching and rotation movements.

In Figure 3, it is shown the curves that illustrate the behavior of the technical system that recreates the embryo-uterus-abdomen area. In the upper part of the central region of the figure, in black background you will notice an animation of the movement of the embryo/baby in real time [6].

The dynamic behavior of the vehicle that pushes, the one who will collide is shown in Figure 4. For this,

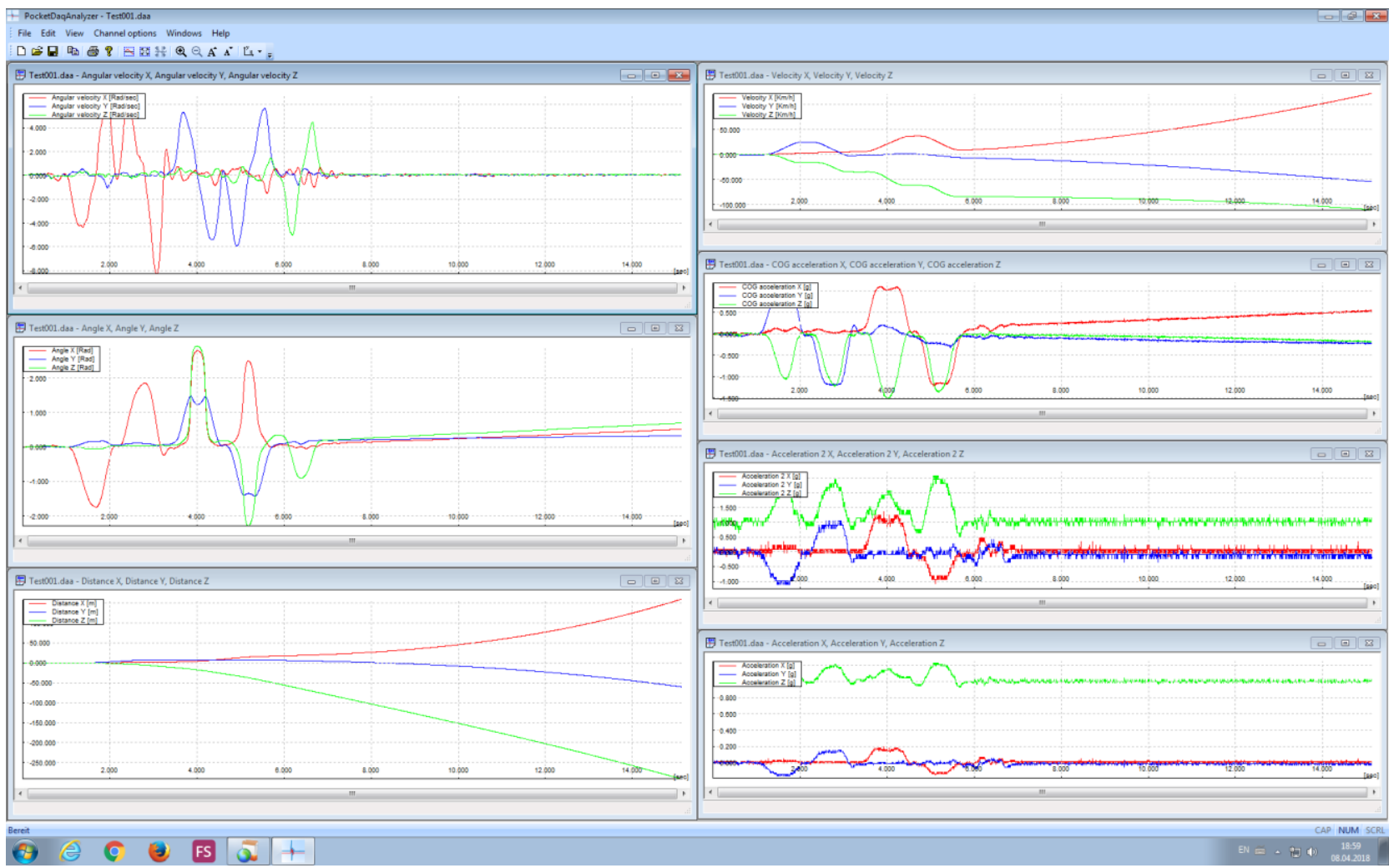

Fig. 2. The interface of the specialized program used for analysis is PocketDAQ Analyzer 


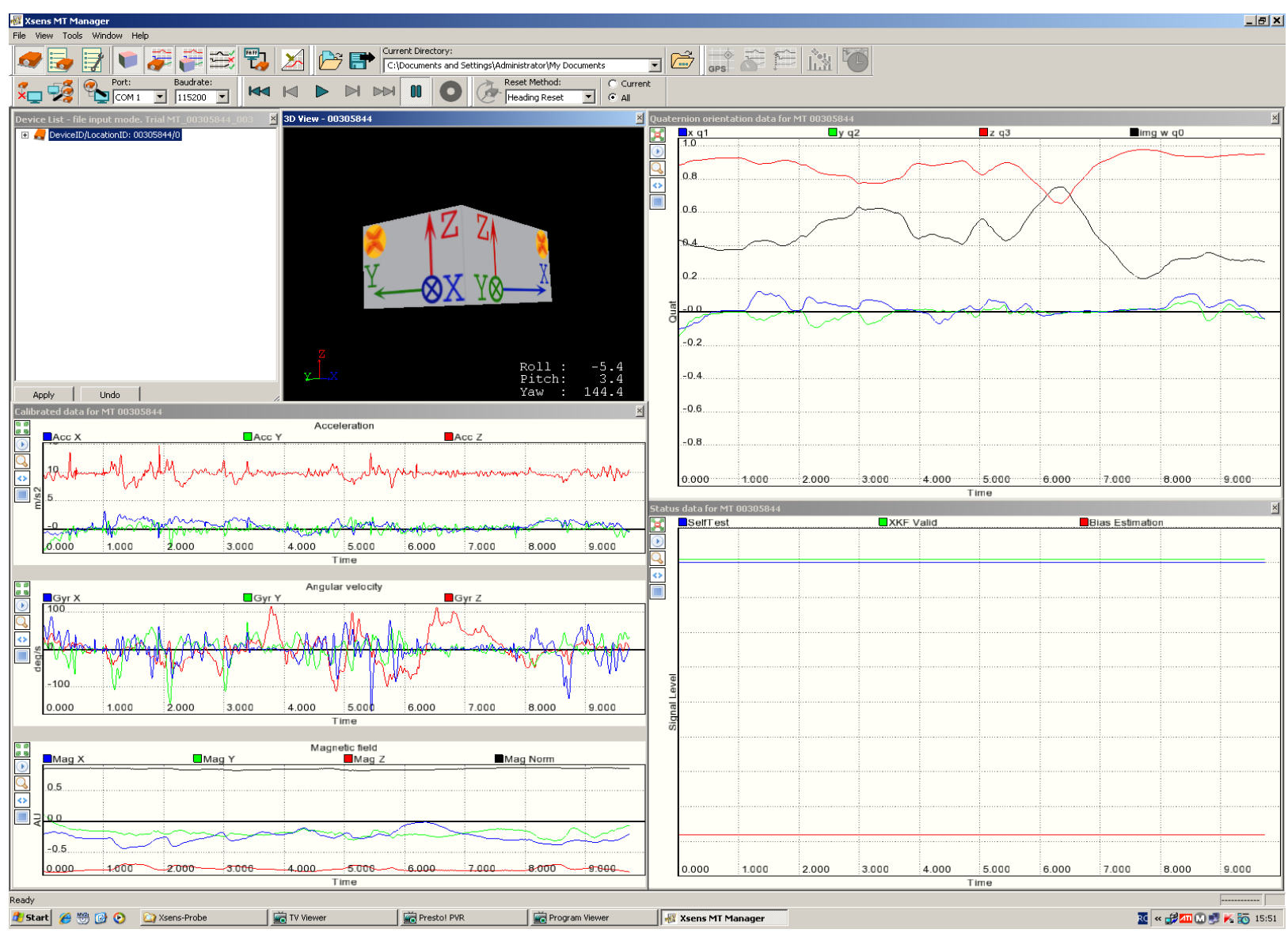

Fig. 3. The specialized analysis interface of the program is Xsens MTi

following hardware was used: a PC Intel(R) Core ${ }^{\mathrm{TM}}$ i5 3.6 $\mathrm{GHz}, \mathrm{RAM} 16.0 \mathrm{~GB}$ and the programs that were used have a user license [7].

The curves presented here have been obtained after a frontal collision with a partial cover with a speed of 10 $\mathrm{m} / \mathrm{s}$ it can be noticed, if you will look closely, the behavior of the vehicles during such a collision. As you can see from the diagrams, the collision has the same characteristics of a prolonged collision, which is a transient dynamic motion regime a dynamic and because of this, it can be seen a significant acceleration of the three axis of the vehicle.

There were a few experimental try-outs performed for different means of protection of the driver when it is a pregnant woman in order to study the stressors applied on a pregnancy of up to 8 weeks [8].

The theoretical and experimental research that are currently being undertaken have one purpose, to come up with new constructive solutions of the technical system used to investigate the mechanical stressors applied on an existing human pregnancy and to provide us with a thorough and global analysis of the results obtained.

\section{Conclusions}

In order to validate the data that was obtained from the measurements performed in laboratory conditions, as well as those obtained in real time conditions, the measurements were analyzed by comparing them with each other. Each of the two investigating tactics require a certain set of steps to be followed which will provide solutions to a few certain problems such as: the manner in which the bruises are created; analyzing the data; isolating the factors that do not have a direct connection with the manner in which the bruises appeared on the body; checking the documents, the norms and the current laws in force that govern the active and passive safety and the protection given to all the people who participate in the road traffic. Each step of the investigations leads to feedback which implies not only redoing some analyses in case some uncertain or contradictory results are obtained, but rather coming up with a series of new hypothesis that can lead to abnormal functioning conditions, which will then be compared with the real manners of bruising or obtaining some extra information regarding the areas of the body close to the area that is studies (when this is necessary).

It is obvious that there is no perfect method to obtain test samples in laboratory conditions that would match the real events when the abdominal stresses could occur (stresses on the pregnancy). The advantages and the disadvantages of each type of experimental tryout must be compared while considering the area of the body that the experiments are focused on.

The main purpose of these experiments is to offer guidelines that would allow the experimental collisions to be performed correctly, while also following the manner in which the tests are performed in general and underlining each equipment in order to detect and 


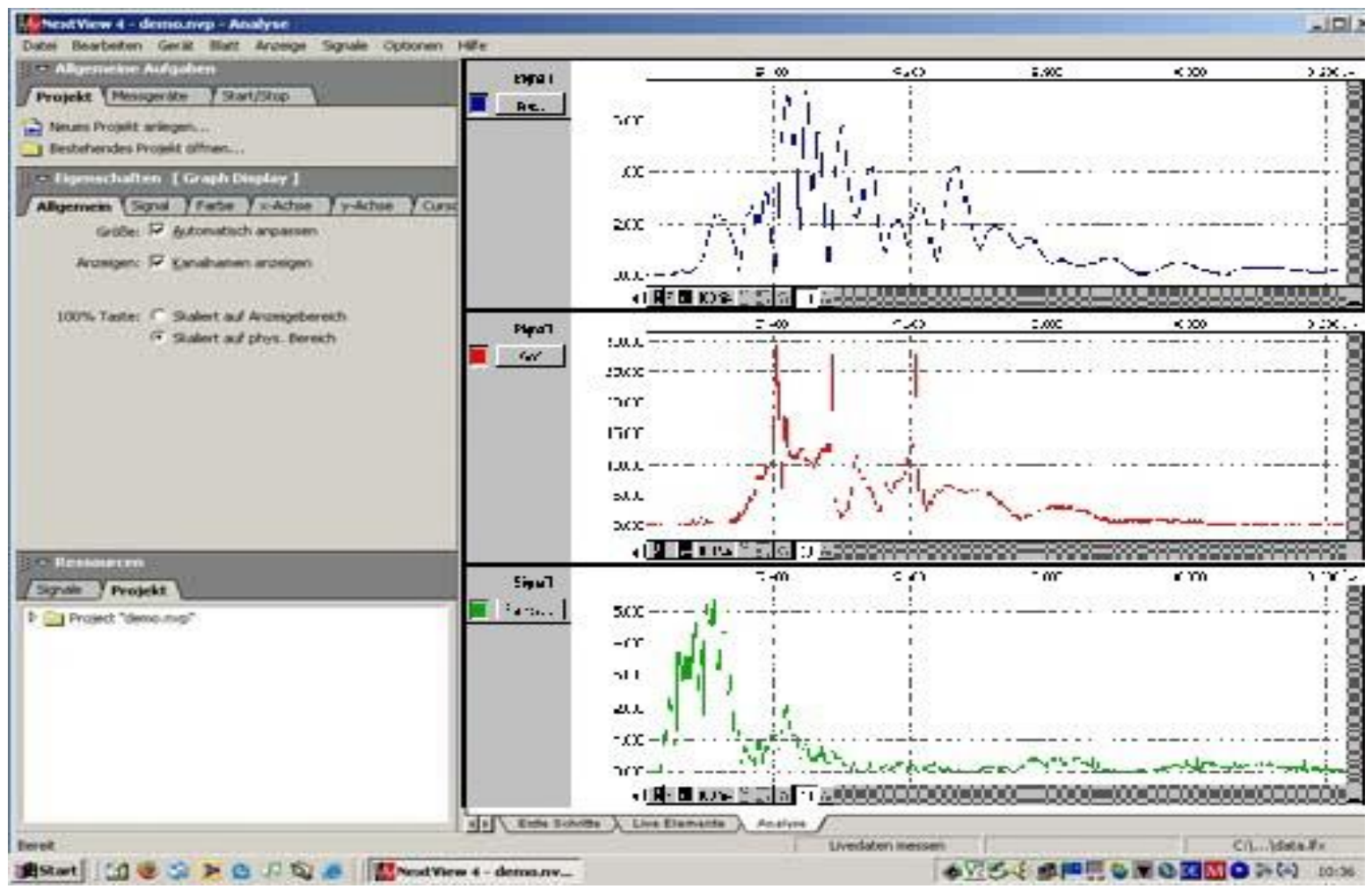

Fig. 4. The interface of the specialized program used for analysis is Next VIEW 4 (2.5)

quantify the type and the size of the stressor acting on the abdomen and on the pregnancy in particular. In these conditions, two main elements will be taken into account that occur when the experimental tests are performed: checking the samples obtained from the experiments by ensuring a structural approach to them and producing some stressing forces on the specially designed stand that would characterize the type of stressors that occur in real collisions. Thus, it is intended to develop the technical systems used for the tests that would allow us to place them in the spaces where they would be most useful.

In this work, it was analyzed only the stressors that act on the victim after a single type and manner of collision, i.e. the frontal collision with a full cover.

\section{References}

1. T.M. Best, J.H. McElhaney, W.E. Garett, B.S. Myers, Axial strain measurements in skeletal muscle at various strain rates, Journal of Biomechanical Engineering JoBE, 11, 7, 262-265, (1995)

2. F. Harold, Mathematical Methods for Accidents Reconstruction, CRC Press Taylor \& Francis Group, USA, (2010)

3. Alexandru. C., Modeling the connections from the mechanical systems through multi body szstems softwares (Modelarea legăturilor din sistemele mecanice prin utilizarea de softuri multibody), 8th
International Conference, Targu Jiu, May 24-26, 2002;

4. W. Thierheimer, Technical Systems from the industry of food and agriculture: from agriculture and food industry: initiation and theoretical foundations (Sisteme tehnice din agricultură şi industrie alimentară: iniţiere şi fundamente teoretice), "Transilvania" University of Brasov, Romania, (2001);

5. R. Thomas, MC-32 System-Bedienungsanleitung, BMC Dr. Schetter, Puchheim, Munchen-Berlin, Germany, (2003);

6. J.S. Wilson, Sensor Technology Handbook, British Library Cataloguing-in-Publication Data Elsevier, USA, (2005);

7. G. Jr. McGwin, S.R. Russell, R.L. Rux, et al. Beliefs, and practices concerning seat belt use during pregnancy. J Trauma 56(3):670-675, (2004);

8. Barsan-Anelli, A., Samaha, R.R., Prasad, P., Kommineni, V amalakkannan, S., Development and Validation of a 2009 Toyota Venza MADYMO Frontal Occupant Model, The National Crash Analysis Center - NCAC 2013-W-003, iulie 2013. 